\title{
Dinâmica de Decomposição e Mineralização de Nitrogênio em Função da Qualidade de Resíduos de Gramíneas e Leguminosas Forrageiras ${ }^{1}$
}

\author{
Hélida Christine de Freitas Monteiro ${ }^{2}$, Reinaldo Bertola Cantarutti ${ }^{3}$, Domicio do Nascimento Junior 4 , \\ Adair José Regazzi ${ }^{5}$, Dilermando Miranda da Fonseca ${ }^{4}$
}

RESUMO - O experimento foi conduzido com o objetivo de avaliar a dinâmica de decomposição e mineralização de nitrogênio de resíduos de algumas gramíneas e leguminosas forrageiras. Utilizaram-se quatorze resíduos, que variaram quanto à procedência e ao local de coleta, e a seleção foi realizada baseando-se nas características qualitativas desses resíduos e utilizando a distância euclidiana média, como medida de dissimilaridade. Desse modo, foram selecionados os resíduos de B. humidicola, B. brizantha, A. pintoi, D. ovalifolium, L. leucocephala, S. guianensis e C. pubescens. A decomposição dos resíduos selecionados foi medida por meio da liberação de $\mathrm{C}_{-} \mathrm{CO}_{2}$. Para a análise dos dados de decomposição, adotou-se o esquema de parcelas subdivididas, em que os resíduos constituíram as parcelas e as avaliações no tempo, as subparcelas. Às quantidades de $\mathrm{CO}_{2}$ evoluídas em função do tempo (horas) ajustou-se uma função logística Para o ensaio de mineralização, foram realizadas amostragens semanais de nitrogênio amoniacal e nítrico, por um período de sete semanas. Observou-se que o teor de polifenóis e a capacidade destes em complexarem proteínas foram os atributos qualitativos que mais afetaram os processos de decomposição e mineralização líquida de nitrogênio. Os resíduos vegetais que apresentaram carbono orgânico mais facilmente degradável apresentaram maior taxa de decomposição (evolução do $\mathrm{CO}_{2}$ ) e mineralização líquida de $\mathrm{N}$. Os resíduos de $C$. pubescens e $A$. pintoi apresentaram as maiores taxas de decomposição e mineralização líquida de N. O resíduo de $B$. brizantha também apresentou alta taxa de decomposição. A nitrificação no solo foi mais intensa sob as condições de mineralização do resíduo de $A$. pintoi .

Palavras-chave: mineralização, resíduos, decomposição, $\mathrm{CO}_{2}$, matéria orgânica

\section{Decomposition Dynamics and Nitrogen Mineralization in Function of Forage Grasses and Legumes Quality Residues}

\begin{abstract}
The decomposition dynamics and mineralization of nitrogen of fourteen residues of grasses and legumes forages varying in origin and collecting places were evaluated. Seven species were selected (B. humidicola, B. brizantha, A.pintoi, D.ovalifolium, L.leucocephala, S. guianensis and C. pubescens), based on qualitative characteristics and using the distance medium Euclidian as dissimilarities measure and then placed in erlenmeyers vases in the laboratory in an entirely randomized fashion. Decomposition data were analyzed using a split-splot design with residues in the main plot and the evaluation on time as the subplot. The decomposition of the selected residues was measured by means of the liberation of $\mathrm{C}-\mathrm{CO}_{2}$, evaluated as a function of time (hours) and adjusted in a logistic function. Weekly sampling of ammonium and nitric nitrogen was realized for a period of seven weeks. If was observed that the amount of polyphenols and their protein complexing ability were the qualitative attribute that affect most the net decomposition and mineralization of $\mathrm{N}$. The residues of $C$. pubescens and $A$. pinto $i$ had the highest rates of decomposition and net $\mathrm{N}$ mineralization along with the residue of $B$. brizantha. Nitrification in the soil was more intense under the mineralization conditions of the $A$. pintoi.
\end{abstract}

Key Words: mineralization, residue, decomposition

\section{Introdução}

Atualmente, estima-se que cerca de 30 milhões de hectares das pastagens estabelecidas no Cerrado estão em algum estádio de degradação, em que a capacidade de suporte não ultrapassa $0,8 \mathrm{UA} /$ ha e a produção animal não alcança $40 \mathrm{~kg} / \mathrm{ha}$ ano de peso vivo (Barcellos, 1996).
O declínio na produtividade das pastagens de braquiária após 4 a 10 anos de pastejo, especialmente em solos arenosos, deve-se, principalmente, à baixa fertilidade natural dos solos, caracterizada pela baixa disponibilidade de fósforo e nitrogênio (Oliveira et al., 1996; Macedo, 1995). A fertilização fosfatada é fundamental para o estabelecimento das pastagens nos solos tropicais, enquanto a adubação nitrogenada

\footnotetext{
${ }^{1}$ Parte da tese apresentada à UFV para obtenção do título Magister Scientiae.

2 Zootecnista, Msc.

3 Professor do Departamento de Solos - UFV. E.mail: domicion@mail.ufv.br

${ }^{4}$ Professor do Departamento de Zootecnia - UFV.

${ }^{5}$ Professor do Departamento de Informática - UFV.
} 
é indispensável para a manutenção da produção da forrageira. Por ser um nutriente bem conservado no sistema solo-planta a deficiência generalizada de fósforo pode ser corrigida, de forma economicamente viável, com a fertilização fosfatada. A deficiência de nitrogênio acentua-se com o declínio nos teores de matéria orgânica, com a grande quantidade de $\mathrm{N}$ retido nos resíduos vegetais (liteira) de elevada relação C:N depositados e a imobilização pelos microrganismos durante a decomposição destes resíduos. Assim, a taxa com que a liteira é reciclada afeta a produtividade das pastagens (Robbins et al., 1989), sendo que o declínio na taxa de crescimento e na qualidade da forrageira relaciona-se com a diminuição na disponibilidade do nitrogênio no solo.

O manejo do pastejo pode contribuir para acentuar a deficiência de N, uma vez que pastagens com excesso de resíduos orgânicos aumentam a quantidade de N imobilizado em forma não-disponível (Cantarutti \& Boddey, 1997; Robbins et al., 1989). Por outro lado, a desfolha intensiva aumenta as exportações do nitrogênio e as perdas devidas à maior exposição do solo.

A fertilização nitrogenada em pastagens tropicais constitui-se em uma prática pouco freqüente, devido, principalmente, aos altos custos do fertilizante e ao caráter extensivo da atividade pecuária. Isto compromete a sustentabilidade da produção das gramíneas forrageiras e, conseqüentemente, a produtividade animal (Robbins et al., 1987; Corsi \& Martha Jr., 1997).

Nos países de clima tropical, onde predominam tecnologias de baixo insumo, as pesquisas têm sido conduzidas visando manter os ecossistemas sustentáveis do ponto de vista ambiental e econômico (Toledo \& Formoso, 1993). Nessas condições, a conservação, a reutilização e, principalmente, a fixação biológica do nitrogênio são fundamentais para obtenção de maior produtividade (Döbereiner, 1997; Giller et al., 1994; Toledo, 1985).

As leguminosas forrageiras, quando fixam $\mathrm{N}_{2}$ por meio da simbiose com bactérias dos gêneros Rhizobium e Bradyrhizobium, constituem-se em alternativa para suprir nitrogênio às pastagens manejadas extensivamente (Toledo, 1985; Cadisch et al., 1993; Thomas, 1992). A transferência do nitrogênio fixado pelas leguminosas para a gramínea associada ocorre principalmente por meio da reciclagem da liteira (Whitney \& Kanehiro, 1967; Thomas, 1992). A fixação de $\mathrm{N}_{2}$ por bactérias associadas às raízes de gramíneas também constitui-se em uma fonte de nitrogênio em pastagens de gramíneas puras (Carvalho, 1986).

Desse modo, é importante conhecer a relação entre qualidade dos resíduos vegetais e a taxa de decomposição e liberação de nutrientes. A relação C:N tem sido utilizada como índice geral da qualidade dos resíduos vegetais, que se relaciona com a sua decomposição. Entretanto, para o entendimento dos mecanismos que regulam os processos de decomposição, são relevantes os teores de nutrientes e de componentes secundários das plantas (Palm \& Sanchez, 1991; Silvaplan et al., 1985).

O objetivo deste estudo foi avaliar a dinâmica de decomposição e mineralização de nitrogênio do material vegetal de gramíneas e leguminosas forrageiras.

\section{Material e Métodos}

\section{Caracterização e seleção dos resíduos vegetais}

Os resíduos vegetais utilizados foram coletados em Viçosa e Coronel Pacheco, em Minas Gerais, e Itabela, na Bahia, sendo provenientes da parte aérea de gramíneas e leguminosas cultivadas em canteiros ou de material morto coletado em solos de pastagens, como mostra a Tabela 1 .

Os resíduos foram secos em estufa com circulação forçada de ar a $70^{\circ} \mathrm{C}$, durante 72 horas, moídos e passados por peneira de $2 \mathrm{~mm}$. Todos os resíduos foram analisados para determinação dos teores de carbono, utilizando-se um analisador elementar LECO modelo CHN 900. Os teores de nitrogênio total, lignina e fibra em detergente ácido (FDA) e a digestibilidade in vitro da matéria seca foram determinados segundo Silva (1990). Dosaram-se também os teores de polifenóis totais solúveis em solução alcoólica, pela reação de Follin-Denis (Anderson \& Ingram, 1989), e a capacidade dos polifenóis em complexar proteína, estimada por meio do método de aglutinação da albumina do soro bovino (BSA) (Waterman \& Mole, 1994). Estabeleceram-se as relações $\mathrm{C}: \mathrm{N}$, lignina:N, lignina:polifenóis, (lignina+polifenóis): $\mathrm{N}$ e polifenóis: $\mathrm{N}$.

Considerando-se as características dos resíduos vegetais (Tabela 1), estes foram agrupados por meio de análise multivariada, com base na matriz de correlação, empregando-se o método de componentes principais e utilizando-se a distância euclidiana média como medida de dissimilaridade. Dessa maneira, foram selecionados os resíduos vegetais de 
Tabela 1 - Caracterização do material vegetal coletado e selecionado para os ensaios de respirometria e mineralização de $\mathrm{N}$

Table 1 - Characterization of the collected and selected material for the respirometry and $N$ mineralization trials

\begin{tabular}{|c|c|c|c|c|c|c|c|c|c|c|c|c|}
\hline $\begin{array}{l}\text { Material vegetal } \\
\text { Vegetal material }\end{array}$ & $\mathrm{C}$ & $\mathrm{N}$ & $\begin{array}{l}\text { FDA } \\
\cdot \cdot(\end{array}$ & $\begin{array}{l}\text { DIG } \\
0) \text {. }\end{array}$ & Lig & Pol & $\begin{array}{l}\mathrm{BSA} \\
\mu \mathrm{g} / \mathrm{mg}\end{array}$ & $\mathrm{C}: \mathrm{N}$ & Lig:N & Pol:N & Lig:Pol & $(\mathrm{Lig}+\mathrm{Pol}): \mathrm{N}$ \\
\hline B. brizantha cv. Marandu ${ }^{1 *}$ & 46,36 & 1,20 & 43,68 & 52,61 & 8,20 & 2,13 & 74,29 & 39 & 7 & 2 & 4 & 9 \\
\hline B. decumbens ${ }^{1 *}$ & 43,29 & 1,74 & 39,14 & 70,92 & 7,46 & 2,21 & 45,71 & 25 & 4 & 1 & 3 & 6 \\
\hline B. brizantha cv. comum ${ }^{1 *}$ & 44,49 & 0,67 & 39,21 & 67,70 & 6,18 & 4,89 & 62,86 & 66 & 9 & 7 & 2 & 17 \\
\hline B. humidicola $2^{* *}$ & 43,33 & 0,40 & 52,35 & 37,63 & 11,46 & 1,17 & 57,14 & 108 & 29 & 3 & 10 & 32 \\
\hline A. pintoi ${ }^{2 *}$ & 39,78 & 2,08 & 49,29 & 61,45 & 13,87 & 2,06 & 40,00 & 19 & 7 & 1 & 7 & 8 \\
\hline D. ovalifolium ${ }^{2 * *}$ & 44,83 & 1,28 & 75,45 & 8,38 & 20,61 & 1,78 & 91,43 & 35 & 16 & 1 & 12 & 17 \\
\hline L. leucocephala ${ }^{1 *}$ & 46,55 & 2,61 & 32,11 & 44,65 & 11,77 & 7,12 & 100,95 & 18 & 5 & 3 & 2 & 7 \\
\hline S. guianensis ${ }^{1 *}$ & 41,24 & 2,00 & 45,12 & 58,23 & 10,70 & 3,56 & 61,00 & 21 & 5 & 2 & 3 & 7 \\
\hline C. pubescens ${ }^{2 *}$ & 39,14 & 1,60 & 57,56 & 33,90 & 15,23 & 2,02 & 38,10 & 24 & 10 & 1 & 8 & 11 \\
\hline P. phaseoloides ${ }^{2 *}$ & 44,42 & 2,03 & 51,27 & 39,24 & 14,02 & 3,34 & 51,43 & 22 & 7 & 2 & 4 & 9 \\
\hline C. mucunoides $^{1 *}$ & 47,05 & 1,75 & 42,56 & 44,25 & 13,33 & 2,87 & 57,14 & 27 & 8 & 2 & 5 & 9 \\
\hline M. sativa $1^{1 *}$ & 45,13 & 3,59 & 37,13 & 62,28 & 11,70 & 2,26 & 87,62 & 13 & 3 & 3 & 5 & 4 \\
\hline C. cajan $^{3 *}$ & 49,08 & 2,53 & 42,36 & 40,46 & 12,75 & 3,99 & 87,62 & 19 & 5 & 2 & 3 & 7 \\
\hline$N$. wightii ${ }^{*}$ & 46,65 & 2,57 & 39,72 & 52,81 & 12,52 & 3,25 & 60,95 & 18 & 5 & 1 & 4 & 6 \\
\hline Coeficiente de variação (\%) & 6 & 43 & 23 & 33 & 28 & 49 & 29 & 76 & 75 & 69 & 57 & 65 \\
\hline
\end{tabular}

Locais de coleta: 1 - Viçosa/MG; 2 - Itabela/BA; e 3 - Coronel Pacheco/MG.

* Parte aérea cortada de plantas crescidas em canteiros; ** Resíduos depositados no solo da pastagem.

$\mathrm{Pol}=$ polifenóis totais solúveis em solução alcoólica $(50 \%)$, dosado pela reação de Follin-Denis (Anderson \& Ingram, 1989$)$; BSA = polifenóis dosados por meio do método de aglutinação do soro bovino (Waterman \& Mole, 1994); C = carbono (Elementar analyzer LECO - CHN 900); Lig = lignina; FDA = fibra em detergente ácido; N = nitrogênio; e DIG = digestibilidade in vitro da matéria seca (Silva, 1990).

Locals of collection: 1 - Viçosa/MG; 2 - Itabela/BA; and 3 - Coronel Pacheco/MG.

* Shoot area of field grown plants; ** Plant residues.

$\mathrm{Pol}=$ total polyfenols soluble in alcohol solution (50\%), determined by Follin-Denis reaction (Anderson \& Ingram, 1989); BSA = polyphenols determined by the agglutination method using bovine serum (Waterman \& Mole, 1994); C = carbon (Elemental analyser LECO - CHN 900); Lig = lignin; FDA = acid detergent fiber; $N=$ nitrogen; and DIG = in vitro dry matter digestibility (Silva, 1990).

Brachiaria humidicola, B. brizantha $\mathrm{cv}$. comum, Arachis pintoi, Centrosema pubescens, Stilosanthes guianensis, Leucaena leucocephala e Desmodium ovalifolium para serem utilizados nos ensaios que seguem.

\section{Mineralização dos resíduos vegetais}

A mineralização dos resíduos foi avaliada por meio da evolução de $\mathrm{C}-\mathrm{CO}_{2}$, utilizando-se o respirômetro de Stotzky descrito por Curl \& Rodriguez-Kabana (1972). Os resíduos vegetais selecionados, com granulometria menor que $2 \mathrm{~mm}$, foram incubados com terra fina seca ao ar de um Latossolo Vermelho-Escuro distrófico com $\mathrm{pH}$ em $\mathrm{H}_{2} \mathrm{O}$ de 5,$8 ; \mathrm{P}$ e $\mathrm{K}$ de 9,4 e $7 \mathrm{mg} / \mathrm{dm}^{3} ; \mathrm{H}+\mathrm{Al}$, soma de bases (SB) e CTC (T) de 11,2; 3,68 e 14,88 cmolc $/ \mathrm{dm}^{3}$; e 4,92 dag/kg de matéria orgânica Não foi realizada correção da acidez nem a adubação do solo.

A massa de cada resíduo vegetal equivalente a $2 \mathrm{~g}$ de carbono, foi misturada a $100 \mathrm{~cm}^{3}$ do solo e acondicionada nas câmaras de incubação do respirômetro (erlenmeyers de $250 \mathrm{~mL}$ ). Também foram montadas unidades contendo o solo sem adição de resíduo vegetal. A umidade do solo foi elevada a $80 \%$ de sua capacidade de campo aplicando-se água destilada que manteve-se próxima à esta condição durante todo o ensaio, considerando que o sistema era fechado. Cada unidade experimental possuía quatro repetições e foram acopladas aleatoriamente ao respirômetro, de modo que o delineamento foi inteiramente casualizado.

As câmaras de incubação foram conectadas ao sistema e submetidas a um fluxo contínuo de ar livre de $\mathrm{CO}_{2}$. $\mathrm{O} \mathrm{CO}_{2}$ resultante da atividade microbiana era arrastado por um fluxo de ar e capturado em um erlenmeyer contendo $100 \mathrm{~mL}$ de $\mathrm{NaOH} 0,25 \mathrm{moL} / \mathrm{L}$. Erlenmeyrs adicionais contendo $100 \mathrm{~mL}$ de $\mathrm{NaOH}$ $0,25 \mathrm{moL} / \mathrm{L}$ foram conectados no início e no final do sistema para funcionar como controles.

Dosou-se o C- $\mathrm{CO}_{2}$ evoluído transferindo-se uma alíquota de $10 \mathrm{~mL}$ da solução de $\mathrm{NaOH} 0,25 \mathrm{moL} / \mathrm{L}$ para outro erlenmeyer, ao qual se adicionaram $10 \mathrm{~mL}$ de $\mathrm{BaCl}_{2}$ 0,025 mol/L e 2-3 gotas de uma solução alcoólica de fenolftaleína $1 \%$ como indicador. Titulou-se com $\mathrm{HCl} 0,1 \mathrm{moL} / \mathrm{L}$ até a solução virar de violeta para incolor.

A massa de $\mathrm{C}-\mathrm{CO}_{2}$ evoluído foi obtida pela fórmula:

\section{R. Bras. Zootec., v.31, n.3, p.1092-1102, 2002}




$$
\mathrm{mg} \mathrm{C}-\mathrm{CO}_{2}=(\mathrm{Vb}-\mathrm{Va}) f 12
$$

em que: Vb e Va são os volumes (mL) de $\mathrm{HCl}$ gastos para titular as amostra dos tratamentos e dos controles; $f$, o fator de correção da concentração de $\mathrm{HCl}$; e 12, o produto entre a concentração do $\mathrm{HCl}(0,1 \mathrm{~mol} / \mathrm{L})$, o fator de diluição (10) e a massa molar de carbono (12).

Durante sete semanas, foram realizadas vinte e seis medições do $\mathrm{C}-\mathrm{CO}_{2}$ evoluído, sendo as treze primeiras a cada 24 horas; três a cada 48 horas; e as dez subseqüentes a cada 72 horas. $\mathrm{O} \mathrm{C}-\mathrm{CO}_{2}$ evoluído acumulado foi expresso em termos absolutos $\left(\mathrm{mg} \mathrm{C}-\mathrm{CO}_{2}\right)$ e em relação à quantidade de carbono adicionado ( $\left.\mathrm{mg} / \mathrm{g} \mathrm{C}-\mathrm{CO}_{2}\right)$.

À evolução acumulada relativa de $\mathrm{C}-\mathrm{CO}_{2}$, expressa em função do tempo (horas), ajustou-se a função logística:

$$
\mathrm{Y}_{\mathrm{i}}=\frac{\alpha}{1+\mathrm{e}^{-\left(\beta+\gamma \mathrm{t}_{\mathrm{i}}\right)}}+\varepsilon_{\mathrm{i}}
$$

O parâmetro $\alpha$ caracteriza a saturação na evolução de $\mathrm{C}-\mathrm{CO}_{2}$, que está diretamente relacionado à quantidade de carbono mais facilmente mineralizável. O parâmetro $\gamma$ caracteriza a constante de evolução de $\mathrm{C}-\mathrm{CO}_{2}$. O parâmetro $\beta$ reflete o tempo necessário para atingir a saturação na evolução de $\mathrm{C}-\mathrm{CO}_{2}$. A magnitude dos parâmetros $\gamma$ e $\beta$ relaciona-se com os aspectos qualitativos dos resíduos e a atividade microbiana. Por sua vez, t é o tempo e $\varepsilon$, o erro aleatório.

No ponto de inflexão da curva, que ocorre no tempo -b/g, atinge-se a metade da saturação na evolução de $\mathrm{C}-\mathrm{CO}_{2}(\alpha / 2)$ e a taxa de evolução de $\mathrm{C}-\mathrm{CO}_{2}$ é máxima $(\alpha \gamma / 4)$. Este valor foi obtido por meio da primeira derivada da função, enquanto o tempo para atingi-la foi obtido com a segunda derivada da função.

Para as análises estatísticas, adotou-se o esquema de parcelas subdivididas, no qual os resíduos vegetais corresponderam às parcelas e as avaliações sucessivas, às subparcelas. As análises estatísticas foram processadas utilizando-se o programa SAS (SAS, 1990).

\section{Mineralização líquida de nitrogênio}

A massa de cada resíduo vegetal, equivalente a $2 \mathrm{~g}$ de carbono, foi misturada a $100 \mathrm{~cm}^{3}$ de solo e acondicionada em potes plásticos de $250 \mathrm{~mL}$. Também foram incluídos potes contendo solo sem a adição de resíduo. A umidade do solo foi inicialmente elevada e mantida durante o ensaio a $80 \%$ de sua capacidade de campo adicionando-se água destilada. Durante o ensaio, a umidade do solo foi monitorada por meio da variação no peso das unidades experi- mentais. Estas foram incubadas em laboratório por oito semanas, dispostas segundo um delineamento inteiramente casualizado com quatro repetições.

Durante sete semanas, determinaram-se em amostras coletadas semanalmente os teores de $\mathrm{N}-\mathrm{NH}_{4}+\mathrm{e}$ $\mathrm{N}-\mathrm{NO}_{3}$ - extraídos em solução de $\mathrm{KCl} 1 \mathrm{~mol} / \mathrm{L}$, empregando-se a relação de 1:10 entre o solo e o extrator. $\mathrm{O}$ $\mathrm{N}-\mathrm{NH}_{4}+$ e o $\mathrm{N}^{-\mathrm{NO}_{3}}$ - foram dosados por métodos colorimétricos descritos por Kempers \& Zweers (1986) e Yang et al. (1998), respectivamente. Amostras de solo sem incubação também foram analisadas.

A mineralização líquida semanal de nitrogênio foi calculada pela variaçãonos teores de nitrogênio inorgânico $\left(\mathrm{N}-\mathrm{NH}_{4}++\mathrm{N}^{-\mathrm{NO}_{3}}{ }^{-}\right)$entre amostras sucessivas.

Os teores iniciais, assim como os teores acumulados de $\mathrm{N}-\mathrm{NO}_{3}$ e de nitrogênio inorgânico, foram submetidos à análise de variância, adotando-se o teste de Tukey, considerando-se a significância a 5\% de probabilidade.

\section{Resultados e Discussão}

\section{Caracterização e seleção dos resíduos vegetais}

Os coeficientes de variação (Tabela 1) evidenciam que os resíduos apresentaram maior variabilidade quanto aos teores de $\mathrm{N}$ de polifenóis e a digestibilidade in vitro da matéria seca. Verificou-se também grande variabilidade para as relações $\mathrm{C}: \mathrm{N}$, lignina:N, polifenóis: $\mathrm{Ne}$ (lignina+polifenóis): $\mathrm{N}$.

Considerando-se simultaneamente as características analisadas por meio da análise de componentes principais, identificaram-se os resíduos mais dissimilares (Figura 1). Na primeira tentativa de agrupamento, na qual os componentes principais um e dois explicaram $71 \%$ da variação total, os resíduos de Brachiaria humidicola e Desmodium ovalifolium destacaram-se como discrepantes entre si e dos demais materiais (Figura 1A). Excluindo-se estes dois resíduos, na segunda tentativa de agrupamento, na qual os componentes principais um e dois explicaram $68 \%$ da variação total, discriminaram-se os resíduos de Brachiaria brizantha cv. Comum, Arachis pintoi, Leucaena leucocephala e Centrosema pubescens e um grupo incluindo oito dos materiais (Figura 1B). Dentro desse grupo selecionou-se o resíduo de Stylosanthes guianensis, que, de acordo com a distância euclidiana média, foi o mais discrepante dos outros quatro materiais selecionados.

Os teores de $\mathrm{N}$ dos resíduos selecionados variaram entre 0,40 (B. humidicola) e 2,61\% 


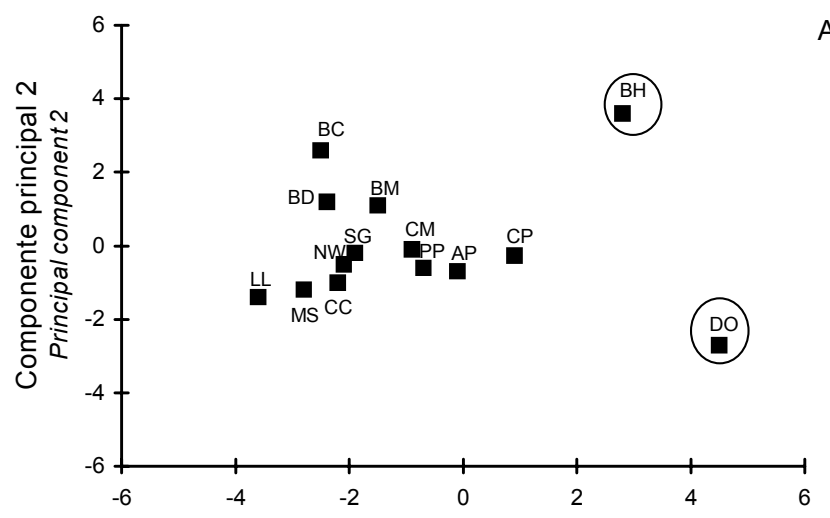

Componente principal 1 Principal component 1

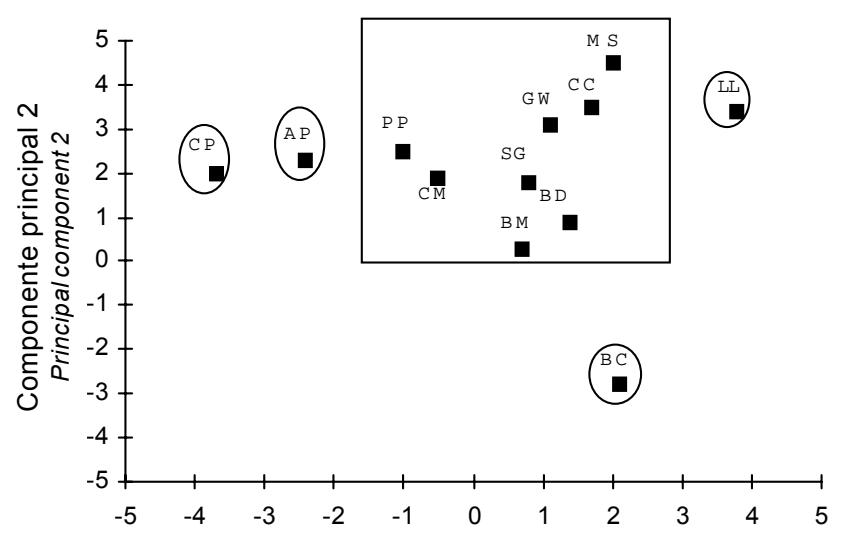

Componente principal 1 Principal component 1

Figura 1 - Dispersão de escores para quatorze resíduos vegetais em relação aos componentes principais um e dois, tendo como base doze características quantitativas, referentes ao primeiro (A) e segundo (B) agrupamentos $\mathrm{BH}=B$. humidicola; $\mathrm{BM}=B$. brizantha $\mathrm{cv}$. Marandu; $\mathrm{BC}=B$. brizantha $\mathrm{cv}$. Comum; $\mathrm{BD}=B$. decumbens; $\mathrm{PP}=P$. phaseoloides; $\mathrm{AP}=A$. pintoi; $\mathrm{CM}=C$. mucunoides; $\mathrm{DO}=$ D. ovalifolium; $\mathrm{LL}=\mathrm{L}$. leucocephala; $\mathrm{SG}=$ S. guianensis; $\mathrm{CP}=$ Centrosema pubescens; $\mathrm{MS}=$ M. sativa $\mathrm{CC}=$ C. cajan $; \mathrm{e} \mathrm{NW}=\mathrm{N}$. wightii.

Figure 1 - Scores dispersion of 14 vegetal residues according to principal components one and two based on 12 quantitative characteristics, in relation to the first $(A)$ and second $(B)$ groupings $B H=B$. humidicola; $B M=B$. brizantha $\mathrm{cv}$. Marandu; $B C=B$. brizantha; $B D=B$. decumbens; $P P=P$. phaseoloides; $A P=$ A. pintoi; $C M=C$. mucunoides; $D O=D$. ovalifolium; $L L=L$. leucocephala; $S G=S$. guianensis; $C P=$ Centrosema pubescens; $M S=M$. sativa; $C C=$ C. cajan; and $N W=N$. wightii.
(L. leucocephala), sendo que estes apresentaram as relações C:N extremas de 108 a 18, respectivamente (Tabela 1). Devido ao baixo teor de N, os resíduos das gramíneas $B$. humidicola e $B$. brizantha apresentaram altas relações $\mathrm{C}: \mathrm{N}$.

Os resíduos das leguminosas selecionadas apresentaram relações $\mathrm{C}: \mathrm{N}$ próximas, com exceção do resíduo de D. ovalifolium, cuja relação foi a mais elevada. Entre as leguminosas, o D. ovalifolium também apresentou os maiores teores de FDA e de lignina, o que contribuiu para as elevadas relações lignina:N, lignina:polifenóis e (lignina+polifenóis): $\mathrm{N}$. $\mathrm{O}$ alto teor de FDA, que indica maior proporção dos componentes fibrosos mais resistentes à digestão, tais como as pentosanas resistentes, celulose, lignina e cutina, é um dos fatores responsáveis pela baixa digestibilidade da forragem (Van Soest, 1994).

Os polifenóis contidos nos resíduos de L. leucocephala e D. ovalifolium apresentaram maior capacidade de complexar proteína, conforme indicam as quantidades precipitadas de soro bovino (Tabela 1). Considerando que o teor de polifenóis totais nos resíduos de $D$. ovalifolium era muito menor, isto indica que estes são mais reativos.

Cinética de decomposição dos resíduos vegetais

As quantidades acumuladas de $\mathrm{C}-\mathrm{CO}_{2}$ evoluídas durante o período de incubação são apresentadas na Figura 2. Observa-se que houve grande variação na quantidade acumulada de $\mathrm{C}-\mathrm{CO}_{2}$ evoluído, sendo que os resíduos de A. pintoi, B. brizantha e C. pubescens proporcionaram os maiores valores, não diferindo entre si $(\mathrm{P}>0,05)$ (Tabela 2).

Assumindo-se uma eficiência de assimilação de C pelos microrganismos de $60 \%$, estimou-se que entre 17 e $128 \%$ do $\mathrm{C}$ adicionado por meio dos diferentes resíduos foi oxidado durante o processo de decomposição (Tabela 2). As estimativas sugerem que as massas dos resíduos de $B$. brizantha, A. pintoi e $C$. pubescens foram totalmente oxidadas e ainda favoreceram oxidação adicional do carbono da matéria orgânica do solo (efeito priming).

O resíduo de $D$. ovalifolium apresentou a menor proporção de carbono oxidado (18\%) em relação a quantidade adicionada, o que se justifica pelo baixo teor de $\mathrm{N}$, pela alta relação $\mathrm{C}: \mathrm{N}$ e elevada capacidade de complexação dos polifenóis (Tabela 2). Observa-se, no entanto, que, apesar de apresentar teores e reatividade dos polifenóis semelhantes, $83 \%$ do $\mathrm{C}$ do resíduo de L. leucocephala foi oxidado. Isso evidencia o papel de 
Tabela 2 - Carbono evoluído $\left(\mathrm{C}-\mathrm{CO}_{2}\right)$, assimilado (C) e total oxidado (Co) expresso em termos absolutos $(\mathrm{mg})$ e em relação (\%) ao C adicionado por meio dos diferentes resíduos

Table 2 - Total $(\mathrm{mg})$ evoluted carbon $\left(\mathrm{C}-\mathrm{CO}_{2}\right)$, assimilated carbon (C) and oxidized carbon (Co) and \% of $\mathrm{C}$ in relation do the $C$ added through the different residues

\begin{tabular}{|c|c|c|c|c|}
\hline Material & $\mathrm{C}-\mathrm{CO}_{2}$ & $\mathrm{C}^{1}$ & $\mathrm{Co}^{2}$ & \\
\hline &. & . $\mathrm{mg}$ & . . . . & $\% 3$ \\
\hline A. pintoi & $1.386^{\mathrm{a}}$ & 2.079 & 3.465 & 128 \\
\hline B. brizantha & $1.279^{\mathrm{a}}$ & 1.918 & 3.196 & 129 \\
\hline C. pubescens & $1.221^{\mathrm{a}}$ & 1.381 & 2.602 & 114 \\
\hline S. guianensis & $999^{a b}$ & 1.498 & 2.497 & 98 \\
\hline L. leucocephala & $916^{\mathrm{ab}}$ & 1.374 & 2.290 & 83 \\
\hline B. humidicola & $464^{\mathrm{bc}}$ & 695 & 1.159 & 34 \\
\hline D. ovalifolium & $397^{b c}$ & 595 & 992 & 18 \\
\hline Solo & $200^{c}$ & 300 & 500 & - \\
\hline Soil & & & & \\
\hline
\end{tabular}

Médias seguidas de mesma letra não diferem entre si, pelo teste Tukey (5\%).

${ }^{1}$ Assumindo eficiência de assimilação de $60 \%$ (Assimilation efficiency of $60 \%$ ).

${ }_{3}^{2} \mathrm{C}-\mathrm{CO}_{2}+\mathrm{C}$.

$\% \mathrm{C}-\mathrm{CO}_{2}$ oxidado $=\frac{\left(\mathrm{C}-\mathrm{CO}_{2} \text { total oxidado do solo }+ \text { residuo }\right)-\left(\mathrm{C}-\mathrm{CO}_{2} \text { total oxidado do solo }- \text { residuo }\right)}{\mathrm{C} \text { adicionado pelo residuo }} \times 100$

outras características dos resíduos, como os teores de $\mathrm{N}$ e de lignina a relação $\mathrm{C}: \mathrm{N}$, como mostra a menor relação (Lig+Pol): $\mathrm{N}$ para tornar o $\mathrm{N}$ biologicamente disponível para atender a demanda de mineralização.

A produção relativa acumulada de $\mathrm{C}-\mathrm{CO}_{2}$ evoluído ajustou-se adequadamente à função logística de crescimento, exceto para o solo sem a adição dos resíduos (Tabela 3), cujos parâmetros caracterizam a cinética de mineralização.

Os maiores valores para saturação na evolução de $\mathrm{C}-\mathrm{CO}_{2}$ (parâmetro $\alpha$ ) foram observados para os resíduos de $C$. pubescens, $A$. pintoi e $B$. brizantha, indicando que esses materiais possuíam maior proporção de $\mathrm{C}$ facilmente oxidável e características qualitativas que favoreceram a sua decomposição.

Embora as estimativas do parâmetro $\alpha$ não tenham correlacionado $(\mathrm{P}>0,05)$ com os indicadores de qualidade dos resíduos, observou-se tendência do teor de polifenóis e a capacidade destes complexarem proteína influenciarem o processo de mineralização, uma vez que os resíduos que apresentaram maior evolução de C- $\mathrm{CO}_{2}$ também apresentaram menores valores para essas características. Esse fato é evidenciado pela estimativa do parâmetro $\alpha$ para os resíduos de L. leucocephala. Apesar deste resíduo apresentar altos teores de $\mathrm{N}$, baixa relação $\mathrm{C}: \mathrm{N}$ e baixo teor de FDA observou-se menor valor para a saturação na evolução de C-
$\mathrm{CO}_{2}$, o que se justifica pelo alto teor de polifenóis solúvel e sua elevada capacidade destes complexarem proteína. Estes resultados concordam com as afirmações de que a decomposição dos resíduos de leguminosas pode ser dificultada pelo alto teor de polifenóis (Vallis \& Jones, 1973) ou pelas elevadas relações polifenol:N (Palm \& Sanchez, 1991) e (lignina+polifenol): N (Fox et al., 1990).

Apesar da alta relação $\mathrm{C}: \mathrm{N}$, teor de polifenóis elevado e com elevada capacidade de complexar proteína, o resíduo de $B$. brizantha comportou-se como material de fácil decomposição, tais como C. pubescens e A. pintoi. Para esse resíduo em particular, os baixos teores de FDA e de lignina, que condicionam alta digestibilidade foram, seguramente, características que favoreceram o processo de decomposição.

Houve pequena variação entre as estimativas da constante de evolução de C- $\mathrm{CO}_{2}$ (parâmetro $\gamma$ ) sugerindo que esta foi pouco sensível às variações qualitativas entre os resíduos (Tabela 4). Assim, a cinética de evolução de $\mathrm{C}-\mathrm{CO}_{2}$ apresentou, aparentemente, o mesmo padrão de crescimento. A taxa de evolução de $\mathrm{C}-\mathrm{CO}_{2}$ máxima foi, no entanto, mais efetiva para caracteriza-los, visto que os maiores valores ocorreram com os resíduos de C. pubescens, A pintoi e $B$. brizantha. Isto mais uma vez evidencia a importância da relação $\mathrm{C}: \mathrm{N}$, dos teores e características de atividades dos polifenóis e dos teores de FDA para decomposição dos resíduos vegetais. Apesar disso demandou-se mais de 250 horas de incubação para que estas taxas fossem atingidas, sendo comparável ao tempo demandado pelos resíduos de $B$. humidicola e D. ovalifolium, que apresentaram os menores valores para a máxima taxa de evolução de $\mathrm{C}-\mathrm{CO}_{2}$. Além do tempo demandado para a recomposição da biomassa do solo, a disponibilidade C prontamente oxidável e de $\mathrm{N}$ são fatores contribuíram para determinar este tempo.

\section{Mineralização líquida de nitrogênio}

Entre os resíduos verificaram-se diferenças significativas $(\mathrm{P}<0,05)$ quanto a mineralização líquida de $\mathrm{N}$ considerando tanto a primeira semana de incubação como a quantidade acumulada no período (Tabela 4).

Na primeira semana de incubação, o resíduo de A. pintoi apresentou a maior taxa de mineralização líquida de $\mathrm{N}(283,4 \mathrm{mg} / \mathrm{kg})$. Os resíduos de B. humidicola e D. ovalifolium também apresentaram mineralização líquida de $\mathrm{N}$ não diferindo $(\mathrm{P}>0,05)$ daquela observada para o resíduo de C. pubescens, sugerindo que $\mathrm{N}$ foi suficiente para atender a baixa

R. Bras. Zootec., v.31, n.3, p.1092-1102, 2002 
1098 Dinâmica de Decomposição e Mineralização de Nitrogênio, em Função da Qualidade de Resíduos de Gramíneas...

Tabela 3 - Estimativas de parâmetros, intervalos de confiança assintótico (IC), coefici-ente de determinação da função logística1 ajustada para evolução relativa2 de $\mathrm{C}_{-} \mathrm{CO}_{2}\left(\mathrm{mg} / \mathrm{g} \cdot \mathrm{h} \mathrm{C}-\mathrm{CO}_{2}\right)$ no ensaio de respirometria, em função do tempo de incubação, e tempo (Horas) necessário para ocorrer a máxima taxa de evolu-ção (mg/g.h C-CO ${ }^{2}$ )

Table 3 - Parameters estimates, assynthotic trust interval (IC), coefficient of logistic function determination 1 adjusted for the C$\mathrm{CO}_{2}\left(\mathrm{mg} / \mathrm{g} \cdot \mathrm{h} \mathrm{C}-\mathrm{CO}_{2}\right)$ relative evolution in the respirometry, according to incubation function and time (Hours) for to occur the maximum evolution rate $\left(\mathrm{mg} / \mathrm{g} . \mathrm{h} \mathrm{C}-\mathrm{CO}_{2}\right)$

\begin{tabular}{|c|c|c|c|c|c|c|}
\hline \multirow[t]{2}{*}{ Material } & \multirow{2}{*}{$\begin{array}{c}\text { Estimativa do parâmetro } \\
\text { Parameter estimate }\end{array}$} & \multicolumn{2}{|c|}{$\mathrm{IC}$} & \multirow[t]{2}{*}{$\mathrm{R}^{2}(\%)$} & \multirow[t]{2}{*}{ Horas } & \multirow[t]{2}{*}{$\mathrm{mg} / \mathrm{g} \cdot \mathrm{h} \mathrm{C}-\mathrm{CO}_{2}$} \\
\hline & & LI3 & LS4 & & & \\
\hline Brachiaria & $\hat{\alpha}=215,35^{*}$ & 205,68 & 224,97 & 97 & 280 & 0,520 \\
\hline Humidicola & $\begin{array}{l}\hat{\beta}=-2,71 * \\
\hat{\gamma}=0,0097^{*}\end{array}$ & $\begin{array}{l}-4,46 \\
0,0089\end{array}$ & $\begin{array}{l}-0,96 \\
0,0105\end{array}$ & & & \\
\hline Brachiaria & $\hat{\alpha}=566,86^{*}$ & 541,38 & 592,34 & 86 & 257 & 1,098 \\
\hline Brizantha & $\begin{array}{l}\hat{\beta}=-1,99 * \\
\hat{\gamma}=0,0078^{*}\end{array}$ & $\begin{array}{l}-2,81 \\
0,0070\end{array}$ & $\begin{array}{l}-1,17 \\
0,0085\end{array}$ & & & \\
\hline Arachis & $\hat{\alpha}=595,00 *$ & 565,48 & 624,52 & 77 & 250 & 1,190 \\
\hline Pintoi & $\begin{array}{l}\hat{\beta}=-2,00 * \\
\hat{\gamma}=0,0080 *\end{array}$ & $\begin{array}{l}-2,95 \\
0,0071\end{array}$ & $\begin{array}{l}-1,05 \\
0,0089\end{array}$ & & & \\
\hline Desmodium & $\hat{\alpha}=143,00 *$ & 136,39 & 149,61 & 79 & 243 & 0,250 \\
\hline Ovalifolium & $\begin{array}{l}\hat{\beta}=-1,70^{*} \\
\hat{\gamma}=0,0070^{*}\end{array}$ & $\begin{array}{l}-2,33 \\
0,0062\end{array}$ & $\begin{array}{l}-1,07 \\
0,0079\end{array}$ & & & \\
\hline Leucaena & $\hat{\alpha}=401,30^{*}$ & 381,33 & 421,27 & 95 & 202 & 0,830 \\
\hline Leucocephala & $\begin{array}{l}\hat{\beta}=-1,68^{*} \\
\hat{\gamma}=0,0083^{*}\end{array}$ & $\begin{array}{l}-2,49 \\
0,0072\end{array}$ & $\begin{array}{l}-0,86 \\
0,0093\end{array}$ & & & \\
\hline Stylosanthes & $\hat{\alpha}=461,02 *$ & 441,44 & 480,61 & 96 & 234 & 0,889 \\
\hline Guianensis & $\begin{array}{l}\hat{\beta}=-1,81^{*} \\
\hat{\gamma}=0,0077^{*}\end{array}$ & $\begin{array}{l}-2,50 \\
0,0069\end{array}$ & $\begin{array}{l}-1,12 \\
0,0085\end{array}$ & & & \\
\hline $\begin{array}{l}\text { Centrosema } \\
\text { Pubescens }\end{array}$ & $\begin{array}{l}\hat{\alpha}=662,56^{*} \\
\hat{\beta}=-2,21^{*} \\
\hat{\gamma}=0,0075^{*}\end{array}$ & $\begin{array}{l}633,66 \\
-3,09 \\
0,0068\end{array}$ & $\begin{array}{c}691,45 \\
-1,34 \\
0,0082\end{array}$ & 86 & 295 & 1,242 \\
\hline $\begin{array}{l}\text { Solo } \\
\text { Soil }\end{array}$ & $\begin{array}{l}\hat{\alpha}=70,03^{*} \\
\hat{\beta}=-1,70 * \\
\hat{\gamma}=0,0075^{*}\end{array}$ & $\begin{array}{l}64,32 \\
-2,89 \\
0,0060\end{array}$ & $\begin{array}{l}75,73 \\
-0,49 \\
0,0090\end{array}$ & 69 & 225 & 0,131 \\
\hline
\end{tabular}

* Significativo a $5 \%$ de probabilidade pelo teste de WALD (Significant at $5 \%$ by WALD test).

$1 \hat{\mathrm{Y}}=\frac{\hat{\alpha}}{1+e^{-(\hat{\beta}+\hat{\gamma} t)}}$

2 C- $\mathrm{CO}_{2}$ evoluído por unidade de $\mathrm{C}$ adicionado por meio dos resíduos. Para o solo considerou-se o conteúdo de $\mathrm{C}$ orgânico.

3,4 Limites inferior e superior, respectivamente (Low and high limits, respectively).

Tabela 4 - Mineralização e imobilização líquida de $\mathrm{N}\left(\mathrm{mg} \cdot \mathrm{kg}^{-1} \mathrm{~N}\right)$ expressa pela variação nos teores de $\mathrm{N}$ inorgânico $\left(\mathrm{NH}_{4}{ }^{+}+\mathrm{NO}_{3}{ }^{-}\right)$, entre duas amostragens subseqüentes, ao longo de sete semanas de incubação do solo com os diferentes resíduos

Table 4 - Nitrogen mineralization and immobilization net $\left(\mathrm{mg} \cdot \mathrm{kg}^{-1} \mathrm{~N}\right)$ expressed by the variation on the inorganic $\left.\mathrm{N}_{(\mathrm{NH}}{ }^{+}+\mathrm{NO}_{3}\right)$ contents between two subsequent samplings, during seven weeks of soil incubation with the different stubbles

\begin{tabular}{|c|c|c|c|c|c|c|c|c|}
\hline \multirow[t]{2}{*}{$\begin{array}{l}\text { Material vegetal } \\
\text { Vegetal material }\end{array}$} & \multicolumn{7}{|c|}{$\begin{array}{l}\text { Semanas de incubação } \\
\text { Weeks of incubation }\end{array}$} & \multirow[t]{2}{*}{$\begin{array}{l}\text { Total acumulado } \\
\text { Total accumulated }\end{array}$} \\
\hline & 1 & 2 & 3 & 4 & 5 & 6 & 7 & \\
\hline & . . & . & . & (mg.kg & & & . & \\
\hline B. humidicola & $56,2^{\mathrm{b}}$ & 0,6 & 29,6 & 9,1 & 2,5 & 29,9 & 4,4 & $345,4^{\mathrm{d}}$ \\
\hline A. pintoi & $238,5^{\mathrm{a}}$ & $-45,5$ & 286,6 & $-123,7$ & 270,8 & $-32,5$ & 331,9 & $1139,1^{\mathrm{a}}$ \\
\hline B. brizantha & $-4,6^{\mathrm{c}}$ & 61,9 & $-8,1$ & 47,6 & $-33,5$ & 59,6 & $-15,7$ & $320,1^{d}$ \\
\hline D. ovalifolium & $55,4^{b}$ & 35,4 & 57,1 & 22,0 & 13,3 & 45,4 & 53,3 & $494,9^{\mathrm{c}}$ \\
\hline L. leucocephala & $-17,7^{\mathrm{c}}$ & 70,3 & $-14,4$ & 65,4 & $-39,1$ & 107,8 & 46,1 & $431,4^{\mathrm{c}}$ \\
\hline S. guianensis & $-7,2^{\mathrm{c}}$ & 49,8 & 9,3 & 33,6 & $-18,4$ & 51,2 & $-1,1$ & $330,2^{\mathrm{d}}$ \\
\hline C. pubescens & $50,7^{\mathrm{b}}$ & 21,5 & 46,8 & $-6,4$ & 36,6 & 29,7 & 103,2 & $495,2^{\mathrm{c}}$ \\
\hline Solo & $-1,3^{\mathrm{c}}$ & 105,8 & $-12,1$ & 121,7 & $-20,8$ & 132,0 & 55,2 & $593,6^{\mathrm{b}}$ \\
\hline
\end{tabular}

Médias seguidas de pelo menos uma mesma letra na coluna (semana 1 e total acumulado) não diferem pelo teste de Tukey (5\%). Means followed by the same letter within the column (week 1 and total accumulated) do not differ (5\%) by Tukey test.

R. Bras. Zootec., v.31, n.3, p.1092-1102, 2002 


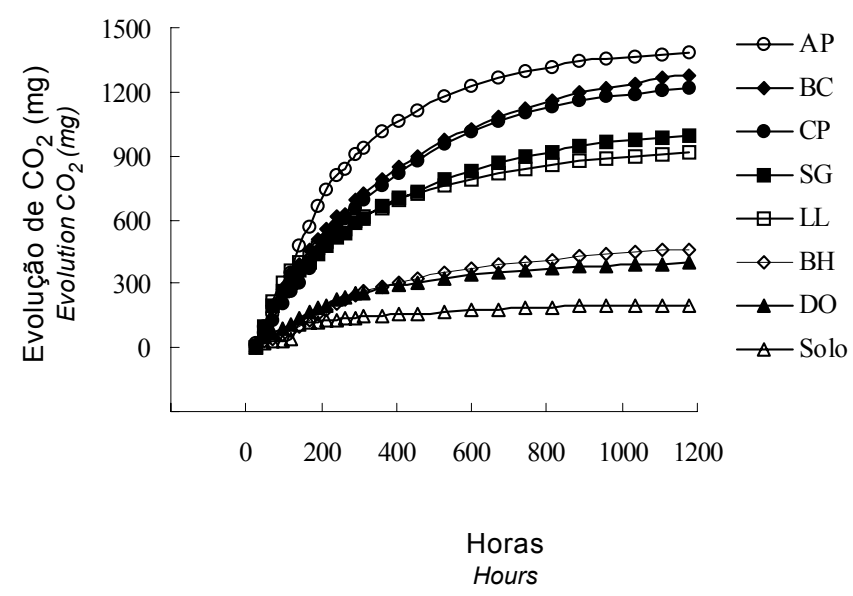

Figura 2 - Produção acumulada de $\mathrm{C}-\mathrm{CO}_{2}(\mathrm{mg})$ durante o período de incubação, no ensaio de respirometria. $\mathrm{AP}=A$. pinto $; \mathrm{BC}=B$. brizantha cv. Comum; $\mathrm{CP}=$ Centrosema pubescens; $\mathrm{SG}$ $=S$. guianensis; $\mathrm{LL}=L$. leucocephala; $\mathrm{BH}=$ B. humidicola; $\mathrm{DO}=D$. ovalifolium.

Figure $2-\mathrm{C}_{-} \mathrm{CO}_{2}(\mathrm{mg})$ accumulated production for the 26 evaluations, during the incubation period, in the respirometry trial. $A P=A$. pintoi; $B C=B$. brizantha cv. Comum; $C P=$ Centrosema pubescens; $S G=S$. guianensis; $L L=L$. leucocephala; $B H=$ B.humidicola; $D O=D$. ovalifolium.

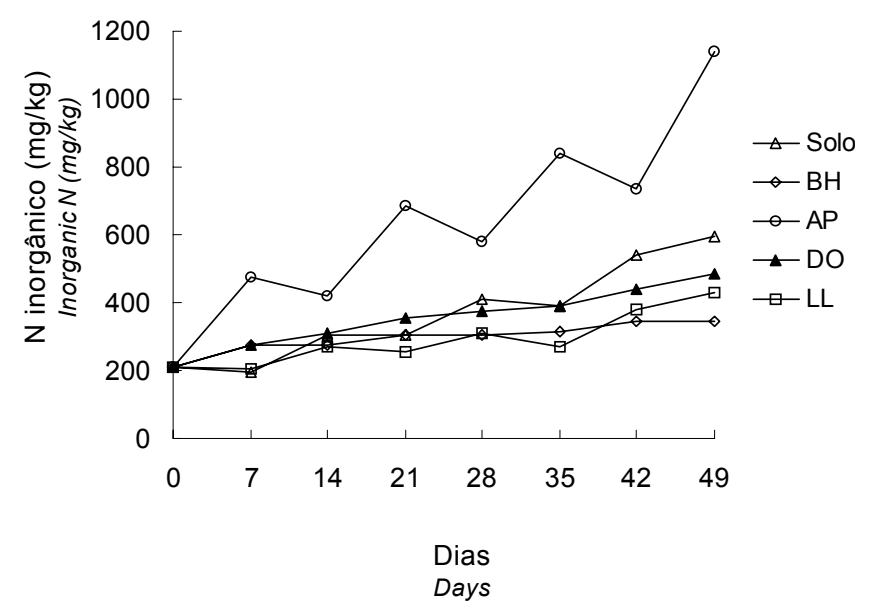

Figura 3 - Variação acumulada dos teores de $\mathrm{N}$ inorgânico $\left(\mathrm{N}-\mathrm{NH}_{4}{ }^{+}+\mathrm{NO}_{3}{ }^{-}\right.$), ao longo de sete semanas de incubação do solo puro e incubado com os diferentes resíduos.

Figure 3 - Variation of inorganic $\mathrm{N}\left(\mathrm{N}_{-} \mathrm{NH}_{4}{ }^{+}+\mathrm{NO}_{3}{ }^{-}\right)$contents, during seven weeks of incubation of pure soil and soil incubated with different plant species residues. taxa de mineralização inicial. Os demais resíduos, incluindo a L. leucocephala com baixa relação C:N, apresentaram imobilização líquida de N, não diferindo $(\mathrm{P}>0,05)$ daquela observada no solo sem a adição de resíduo.

Considerando o balanço no período de sete semanas todos os resíduos condicionaram mineralização líquidas (Tabela 4). Concordando com o padrão de decomposição demonstrado pela evolução de $\mathrm{C}-\mathrm{CO}_{2}$ o resíduo de $A$. pintoi condicionou a maior quantidade acumulada de $\mathrm{N}$ mineralizado. Apesar de apresentar características semelhantes, quanto à relação C:N, teor lignina e digestibilidade o resíduo de L. leucocephala condicionou mineralização líquida tão baixa quanto aquela verificada com os resíduos de $B$. humidicola e $B$. brizantha, o que se deve, possivelmente, pelo ao alto teor e da elevada capacidade de complexar proteínas dos polifenóis nesta leguminosa. Silvalapan et al. (1985) observaram que, independentemente do elevado teor, a biodisponibilidade do $\mathrm{N}$ em resíduos vegetais foi limitada pelo alto teor de polifenóis. Assim, Palm \& Sanchez (1991) também concluíram que a quantidade de $\mathrm{N}$ em L. leucocephala não foi suficiente para atender a demanda de mineralização devido aos altos teores de polifenóis e a capacidade destes complexarem proteínas.

A evolução na mineralização do $\mathrm{N}$ durante $\mathrm{o}$ período de incubação diferiu entre os resíduos, conforme ilustra a Figura 3. A evidente alternância de ciclos de mineralização e imobilização líquidas para o resíduo de $A$. pintoi, pode estar relacionada a variações cíclicas na biomassa do solo decorrente da intensa mineralização do resíduo.

Em decorrência da intensa mineralização o resíduos de $A$. pintoi condicionou maior $(\mathrm{P}<0,05)$ nitrificação líquida na primeira semana de incubação e maior quantidade nitrato produzido no período (Tabela 5). Os demais resíduos condicionaram nitrificação líquida acumulada significativamente menor $(\mathrm{P}<0,05)$ do que aquela verificada no solo sem a adição de resíduos. A estreita relação entre as variações nos teores de $\mathrm{NH}_{4}+$ e $\mathrm{NO}_{3}$ - durante o período de incubação (Figura 4) evidenciam que resíduos vegetais que proporcionam intensa mineralização favorecem a nitrificação, o que potencializa as perdas de nitrogênio. 
1100 Dinâmica de Decomposição e Mineralização de Nitrogênio, em Função da Qualidade de Resíduos de Gramíneas...
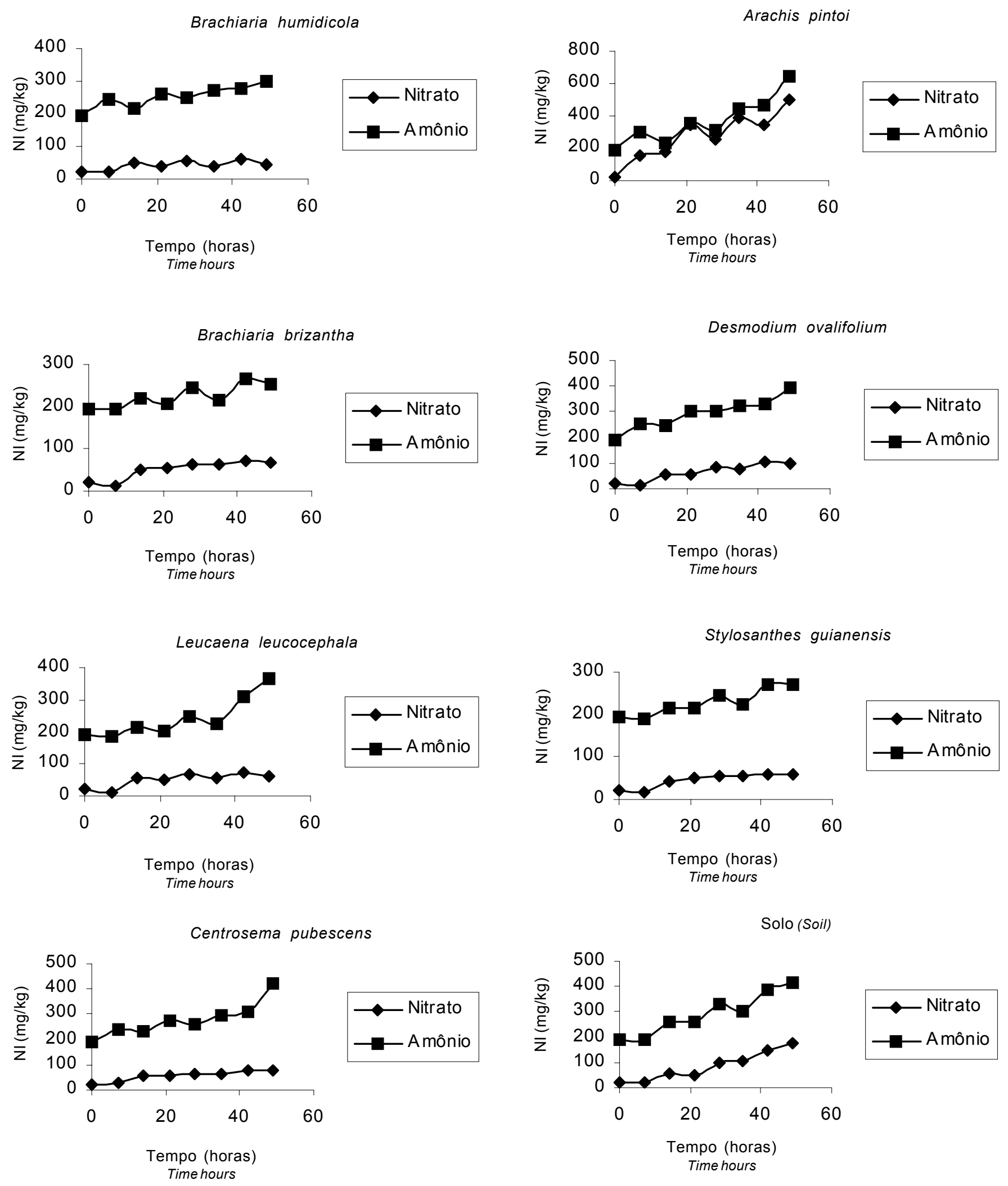

Figura 4 - Variação acumulada dos teores de $\mathrm{NO}_{3}{ }^{-}$e $\mathrm{NH}_{4}{ }^{+}$, ao longo de sete semanas de incubação do solo puro e incubado com os diferentes resíduos.

Figure 4 - Accumulated variation of $\mathrm{NO}_{3}{ }^{-}$and $\mathrm{NH}_{4}{ }^{+}$content, during seven weeks of incubation of pure soil and soil incubated with different plant species residues. 
Tabela 5 - Nitrificação líquida expressa pela variação nos teores de $\mathrm{N}-\mathrm{NO}_{3}^{-}\left(\mathrm{mg}^{-} \mathrm{kg}^{-1} \mathrm{~N}\right)$, entre duas amostragens subseqüentes, ao longo de sete semanas de incubação do solo com os diferentes resíduos

Table 5 - Net nitrification expressed by the variation on the $\mathrm{N}_{-} \mathrm{NO}_{3}^{-}\left(\mathrm{mg}^{-} \mathrm{kg}^{-1} \mathrm{~N}\right)$ contents between two subsequent samplings, during seven weeks of soil incubation with the different plant residues

\begin{tabular}{|c|c|c|c|c|c|c|c|c|}
\hline \multirow[t]{2}{*}{$\begin{array}{l}\text { Material vegetal } \\
\text { Vegetal material }\end{array}$} & \multicolumn{7}{|c|}{$\begin{array}{c}\text { Semanas de incubação } \\
\text { Weeks of incubation }\end{array}$} & \multirow[t]{2}{*}{$\begin{array}{l}\text { Total acumulado } \\
\text { Total accumulated }\end{array}$} \\
\hline & 1 & 2 & 3 & 4 & 5 & 6 & 7 & \\
\hline & \multicolumn{7}{|c|}{$\left(\mathrm{mg} \cdot \mathrm{kg}^{-1} \mathrm{~N}\right)$} & \\
\hline B. humidicola & $1,9^{b}$ & 28,2 & $-14,3$ & 19,5 & $-17,1$ & 22,6 & $-16,6$ & $45,0^{e}$ \\
\hline A. pintoi & $130,3^{\mathrm{a}}$ & 26,3 & 162,2 & $-82,7$ & 136,4 & $-53,8$ & 158,5 & $497,9^{\mathrm{a}}$ \\
\hline B. brizantha & $-7,4^{b}$ & 37,7 & 4,5 & 8,4 & $-2,2$ & 8,3 & $-2,5$ & $67,6^{\mathrm{de}}$ \\
\hline D. ovalifolium & $-4,1^{b}$ & 42,6 & $-0,8$ & 24,7 & $-8,2$ & 34,1 & $-8,6$ & $100,4^{\mathrm{c}}$ \\
\hline L. leucocephala & $-9,4^{b}$ & 42,8 & $-4,3$ & 17,1 & $-12,1$ & 20,4 & $-11,8$ & $63,4^{\text {de }}$ \\
\hline S. guianensis & $-5,8^{b}$ & 26,3 & 9,3 & 2,8 & 0,9 & 6,5 & 0,3 & $61,1^{\mathrm{de}}$ \\
\hline C. pubescens & $6,7^{b}$ & 26,3 & 0,8 & 12,1 & $-2,6$ & 15,5 & $-3,4$ & $76,1^{\mathrm{cd}}$ \\
\hline Solo & $-1,3^{b}$ & 36,3 & $-7,8$ & 50,5 & 5,7 & 45,0 & 30,4 & $179,5^{\mathrm{b}}$ \\
\hline
\end{tabular}

Médias seguidas de pelo menos uma mesma letra na coluna (semana 1 e total acumulado) não diferem pelo teste de Tukey a $5 \%$. Means followed by the same letter within a column (week 1 and total accumulated) did not differ by Tukey test at $5 \%$.

\section{Conclusões}

A mineralização dos resíduos foi afetada pelos teores e pela capacidade de complexação dos polifenois, sendo que os resíduos de e $A$. pintoi apresentaram as maiores taxas de decomposição e mineralização líquida de N, assim como de nitrificação. O resíduo da gramíneas $B$. brizantha também apresentou alta taxa de decomposição.

\section{Literatura Citada}

ANDERSON, J.M.; INGRAM, J.S.I. Tropical soil biology and fertility: a handbook of methods. Wallingford: CAB International, 1989. 171p.

BARCELLOS, A.O. Sistemas extensivos e semi-intensivos de produção: pecuária bovina de corte nos cerrados. In: SIMPÓSIO SOBRE O CERRADO, 8., 1996, Brasília, DF. Anais... Planaltina, DF: EMBRAPA - CPAC, 1996. p.130-36.

CADISCH, G.; CARVALHO, E.F.; SUHET, A.R; et al. The importance of legume $\mathrm{N}_{2}$-fixation in sustaintability of pastures in the cerrados of Brazil. In: INTERNATIONAL GRASSLANDS CONGRESS, 17., 1993, Palmerston North. Proceedings ... Palmerston North: New Zealand Grassland Association, 1993. p.1915-1918.

CANTARUTTI, R.B.; BODDEY, R.M. Transferência de nitrogênio das leguminosas para as gramíneas. In: SIMPÓSIO INTERNACIONAL SOBRE PRODUÇÃO ANIMAL EM PASTEJO, 1997, Viçosa, MG. Anais... Viçosa, MG: Universidade Federal de Viçosa, 1997. p.431-445.

CARVALHO, M.M. Fixação biológica como fonte de nitrogênio para pastagens. In: SIMPÓSIO SOBRE CALAGEM E ADUBAÇÃO DE PASTAGENS, 1985, Nova Odessa. Anais... Piracicaba: PATAFOS, 1986. p.125-143.

CORSI, M.; MARTHA JR., G.B. Manutenção da fertilidade do solo em sistemas intensivos de pastejo rotacionado.
In: SIMPÓSIO SOBRE O MANEJO DA PASTAGEM, 14., 1997, Piracicaba. Anais...Piracicaba: Fundação de Estudos Agrários "Luiz de Queiroz”, 1997. p.161-192.

CURL, E.A.; RODRIGUEZ-KABANA, R. Microbial interactions. In: WILKINSON, R.E. (Ed.) Research methods in weed science. Atlanta: Southern Weed Society, 1972. p.162-194.

DÖBEREINER, J. Biological nitrogen fixation in the tropics: social and economic contributions. Soil Biology Biochemistry, v.29, n.6, p.771-774, 1997.

FOX, R.H.; MYERS, R.J.K.; VALLIS, I. The nitrogen mineralization rate of legume in soil as influenced by their poyphenol, lignin and nitrogen contents. Plant and Soil, v.129, n.2, p.251-259, 1990.

KEMPERS, A.J.; ZWEERS, A. Ammonium determination in soil extracts by the salicylate method. Communication in Soil Science Plant Analyze, v.17, n.7, p.715-723, 1986.

MACEDO, M.C.M. Pastagens no ecossistema cerrados: pesquisa para o desenvolvimento sustentável. In: SIMPÓSIO SOBRE PASTAGENS NOS ECOSSISTEMAS BRASILEIROS: PESQUISAS PARA O DESENVOLVIMENTO SUSTENTÁVEL, 1995, Brasília. Anais... Brasília: Sociedade Brasileira de Zootecnia, 1995. p.28-62.

PALM, C.A.; SANCHEZ, P.A. Nitrogen release from the leaves of some tropical legumes as affected by their lignin and polyphenol contents. Soil Biology Biochemistry, v.23, n.1, p.83-88, 1991.

ROBBINS, G.B.; BUSHELL, J.J.; BUTLER, K.L. Decline in plant and animal production from ageing pastures of green panic (Panicum maximum var. trichoglume). Journal of Agricultural Science, v.108, n.2, p.407-417, 1987.

ROBBINS, G.B.; BUSHELL, J.J.; McKEON, G.M. Nitrogen immobilization in decomposing litter contributes to productivity decline in ageing pastures of green panic (Panicum maximum var. trichoglume). Journal of Agricultural Science, v.113, p.401-406, 1989.

SAS INSTITUTE. SAS/STAT user's guide: statistics. 4.ed. Version 6. v.1. Cary: 1990.

R. Bras. Zootec., v.31, n.3, p.1092-1102, 2002 
SILVA, D.J. Análise de alimentos: métodos químicos e biológicos. Viçosa, MG: Universidade Federal de Viçosa, 1990. 165p.

SIVALAPAN, K.; FERNANDO, R.; THENABADU, M.W. Nmineralization in polyphenol-rich plant residues and their affect on nitrification of applied ammonium sulphate. Soil Biology Biochemistry, v.17, n.4, p.547-551, 1985.

THOMAS, R.J. The role of legume in the nitrogen cycle of productive and sustainable pastures. Grass and Forage Science, v.47, n.2, p.133-142, 1992.

TOLEDO, J.M. Pasture development for cattle production in the major ecosystems of the tropical American lowlands. In: INTERNATIONAL GRASSLANDS CONGRESS, 15. 1985, Kyoto, Japan. Proceedings... Kyoto, Japan: The Science Council of Japan, 1985. p.74-81.

TOLEDO, J.M.; FORMOSO, D. Sustainability of sown pastures in the tropics and subtropics. In: INTERNATIONAL GRASSLAND CONGRESS, 17., 1993, Palmerston North. Proceedings... Palmerston North: New Zealand Grassland Association, 1993. p.1891-1896.

VALLIS, I.; JONES, R.J. Net mineralization of nitrogen in leaves and leaf liteira of Desmodium intortum and Phaseolus atropurpureus mixed with soil. Soil Biology Biochemistry, v.5, n.4, p.391-398. 1973.
Van SOEST, P.J. Cell wall matrix interactions and degradation. Session synopsis. In: JUNG, H.G.; BUXTON, D.R.; HATFIRLD, R.D. et al. (Eds.) Forage cell wall structure and digestibility. Madison: American Society of Agronomy, 1994. p.377-395.

WATERMAN, G.P.; MOLE, S. Analysis of phenolic plant metabolites. In: LAWTON, J.H.; LIKENS, G.E. (Eds.). Methods in ecology. Oxford: BSP, 1994. p.120.

WHITNEY, A.S.; KANEHIRO, Y. Pathways of nitrogen transfer in some tropical legume-grass associations. Agronomy Journal, v.59, n.6, p.585-588, 1967.

YANG, J.E.; SKOGLEY, E.O.; SCHAFF, B.E. et al. A simple spectrometric determination of nitrate in water, resin, and soil extracts. Soil Science Society of America Journal, v.62, n.4, p.1108-1115, 1998.

Recebido em: 12/07/01

Aceito em: 27/02/02 